\title{
The activation of NLRP3-inflammsome by stimu- lation of diesel exhaust particles in lung tissues from emphysema model and RAW 264.7 cell line
}

\author{
Soo-Taek Uh ${ }^{1}$, So My Koo ${ }^{1}$, Yangki Kim ${ }^{1}$, Kiup Kim ${ }^{1}$, Sungwoo Park ${ }^{2}$, An Soo Jang ${ }^{2}$, Dojin Kim², \\ Yong Hoon $\mathrm{Kim}^{3}$, and Choon-Sik Park ${ }^{2}$
}

${ }^{1}$ Division of Allergy and Respiratory Medicine, Soon Chun Hyang University Seoul Hospital, Seoul; ${ }^{2}$ Genome Research Center and Division of Allergy and Respiratory Medicine, Soon Chun Hyang University Bucheon Hospital, Bucheon; ${ }^{3}$ Division of Respiratory Medicine, Soon Chun Hyang University Cheonan Hospital, Cheonan, Korea

Received: January 29, 2016 Revised : July 14, 2016 Accepted: October 6, 2016

\section{Correspondence to}

Choon-Sik Park, M.D.

Division of Allergy and Respiratory Medicine, Department of Internal Medicine, Soon Chun Hyang University Bucheon Hospital, 170 Jomaru-ro, Wonmi-gu, Bucheon 14584, Korea

Tel: $+82-32-621-5105$

Fax: +82-32-621-5023

E-mail: schalr@schmc.ac.kr
Background/Aims: Diesel exhaust particles (DEPs) lead to elevation of reactive oxygen species, which can activate the nucleotide-binding oligomerization domain-like receptor (NLR) family members containing the pyrin domain 3 (NLRP3)-inflammasome. In this study, we elucidated whether NLRP 3 -inflammasome is activated by DEPs and whether antioxidants (N-acetylcysteine [NAC]) could inhibit such activation.

Methods: RAW 264.7 cells and ex vivo lung tissues explants obtained from elastase-induced emphysema animal models were stimulated with cigarette smoking extract (CSE), DEPs, and lipopolysaccharide, and levels of interleukin-1 $\beta$ (IL-1 $\beta$ ), caspase-1 and nucleotide-binding oligomerization domain-like receptor (NLR) family members containing the pyrin domain (NLRP3)-inflammasome were assessed by Western blotting and immunohistochemistry.

Results: NAC and caspase-1 inhibitor suppressed CSE- and DEP-induced secretion of IL-1 $\beta$ in RAW 264.7 cells. The expression levels of the NLRP3-inflammasome and caspase-1 were upregulated in RAW 264.7 cells by stimulation with CSE and DEPs and were inhibited by NAC. CSE and DEPs increased the secretion of IL-1 $\beta$ in lung tissues from both the normal and elastase-induced emphysema groups. The secretion of IL-1 $\beta$ by CSE and DEPs was increased in the elastin-induced emphysema group more than that in the normal group (CSE: $309 \pm 19 \mathrm{pg} / \mathrm{mL}$ vs. $151 \pm$ $13 \mathrm{pg} / \mathrm{mL}$, respectively, $p<0.05$; DEP: $350 \pm 24 \mathrm{pg} / \mathrm{mL}$ vs. $281 \pm 15 \mathrm{pg} / \mathrm{mL}$, respectively, $p<0.05)$. NAC inhibited CSE- and DEP-induced IL-1 $\beta$ secretion in both the normal and elastase-induced emphysema groups. NLRP3-inflammasome expression as determined by immunohistochemistry was increased by CSE and DEPs in both the normal and elastin-induced emphysema groups, and was suppressed by NAC. Conclusions: The NLRP3-inflammasome is activated by DEPs in ex vivo tissue explants from elastase-induced emphysema animal model, and this activation is inhibited by NAC.

Keywords: Pulmonary disease, chronic obstructive; Emphysema; Inflammasomes; Vehicle emissions; Pancreatic elastase 


\section{INTRODUCTION}

Chronic obstructive pulmonary disease (COPD) is defined as a common, preventable, and treatable disease characterized by limited airflow that is persistent, typically progressive, and associated with chronic pulmonary inflammatory responses to noxious particles and gases [1]. The incidence of COPD has increased in the past few decades and is estimated to be ranked as the third most common cause of death by 2020 [2]. A previous cross-sectional study reported that the mortality rate increases to $2.5 \%$ in COPD patients with acute exacerbation of COPD (AECOPD) [3]. In addition, acute exacerbation can reduce long-term survival of patients with COPD [4]. The two known common causes of AECOPD appear to be respiratory infections and air pollution.

The inflammasome consists of nucleotide-binding oligomerization domain-like receptor (NLR) family members containing the pyrin domain (NLRP), the adaptor molecule apoptosis-associated speck-like protein containing a CARD (ASC) domain, and caspase-1 [5]. In response to pathogens, sterile tissue damage, and metabolic stress, $\mathrm{NLRP}_{3}$ binds to procaspase-1 through ASC, subsequently activating caspase-1. Activation of capase- 1 leads to maturation of interleukin-1 $\beta$ (IL-1 $\beta)[5,6]$. Recently, the NLRP3-inflammasome has been hypothesized to be involved in the pathogenesis of COPD, although no direct evidence has been reported. Cigarette smoking elevates IL-1 $\beta$ levels in the human lung [7]. IL18, a member of the IL-1 cytokine family, is also elevated in the sputum and serum of patients with COPD $[8,9]$. These findings suggest that inflammasome is closely related to the pathogenesis of COPD. Furthermore, AECOPD may be related to NLRP3-inflammasome because about two-thirds of AECOPD cases are associated with viral or bacterial infection of the respiratory tract [10], which leads to activation of the NLRP3-inflammasome. In fact, nontypeable Haemophilus influenzae-induced inflammation in respiratory cells and tissues results in the upregulation of NOD-like receptor pyrin domain-containing 3 (NLRP3)-inflammasome [11]. This finding suggests a certain role of the activation of NLRP3-inflammasome in the pathogenesis of AECOPD.

Diesel exhaust particles (DEPs) produced by diesel engine vehicles is an important constituent of particulate matter air pollution $[12,13]$. Because of the large number of hazardous chemicals present, inhalation of DEPs likely exert harmful effects on the airways of COPD patients. These harmful effects are suggested by the findings of increased secretion of proinflammatory cytokines and reactive oxygen species induced by DEPs [14,15]. DEP exposure leads to elevation of reactive oxygen species, which can activate the NLRP3-inflammasome [16]. Therefore, we speculated that DEP-induced activation of NLRP3-inflammasome may be related to the pathogenesis of AECOPD.

In the present study, we investigated whether the NL$\mathrm{RP}$-inflammasome is activated in an elastase-induced emphysema model by challenge with DEPs, and whether antioxidants inhibit DEP-induced activation of the $\mathrm{NLRP}_{3}$-inflammasome in vitro.

\section{METHODS}

\section{Cell culture}

RAW 264.7 cells were cultured at $37^{\circ} \mathrm{C}$ in $5 \% \mathrm{CO}_{2}$ in Dulbecco's modified Eagle's medium (DMEM) medium (Gibco, Langley, OK, USA) supplemented with 10\% heatinactivated fetal calf serum (Gibco), $50 \mathrm{IU} / \mathrm{mL}$ penicillin, and $100 \mathrm{mg} / \mathrm{mL}$ streptomycin. Cells were subcultured every 3 to 4 days and seeded at $10^{6} / \mathrm{mL}$ in six-well plates (Nalge Nunc, Rochester, NY, USA).

\section{Animals}

Experiments protocols were performed according to the Guidelines for the Care and Use of Laboratory Animals of the National Health Institute, and were approved by the Animal Ethics Committee of Soon Chun Hyang University Bucheon Hospital (SCHBC-animal-201409). $\mathrm{C}_{57} \mathrm{BL} / 6$ female mice, at 12 weeks of age, were purchased from Central Lab Animal Inc. (Seoul, Korea) and were used in the present study. The animals were housed in a temperature- and humidity-controlled room with free access to water and standard laboratory food. Mouse pulmonary emphysema was induced by one-time intratracheal administration of $15 \mu \mathrm{g}$ of porcine pancreatic elastase (PPE) (E788, Sigma-Aldrich, St. Louis, MO, USA) in $50 \mu \mathrm{L}$ of phosphate-buffered saline (PBS) while control mice received $50 \mu \mathrm{L}$ of sterile PBS [17]. After 3 weeks of intratracheal instillation, animals were euthanized. Each group consisted of 12 mice, of which six were used 
for lung histology and bronchoalveolar lavage (BAL) and the other six for ex vivo explants culture. For the explants culture, six pieces of lung tissues (20 to $30 \mathrm{mg} / \mathrm{each}$ ) were treated similarly as the cell culture.

\section{Preparation of cigarette smoking extract}

The cigarette smoking extract (CSE) was produced using a modification of the method of Smelter et al. [18]. Briefly, a 50-mL plastic syringe was attached to the smoking apparatus (Smoking Tester System, Three Shine Inc., Daejeon, Korea) in the atmosphere. Smoke (35 mL) from Korean cigarettes (THIS, KT\&G, Seoul, Korea) were slowly drawn into the attached syringe and passed through $30 \mathrm{~mL}$ of cell culture medium (DMEM). The CSE solution was then filtered and used within 30 minutes. The concentration of the CSE solution thus produced was considered to be $100 \%$.

\section{In vitro cell culture}

After 18 hours of starvation, cells were stimulated with various concentrations of CSE (5\% to 30\%), DEPs (5\% to 30\%) (Diesel Particular Matter; Standard Reference Material 165ob; average particle diameter $0.18 \mu \mathrm{m}$; surface area, $108 \mathrm{~m}^{2} / \mathrm{g}$; National Institute of Standards and Technology, Gaithersburg, MD, USA), or $1 \mathrm{mg} / \mathrm{mL}$ lipopolysaccharide (LPS) as the positive control. The concentration and stimulation time of CSE and DEPs were analyzed by measuring the IL-1 $\beta$ level in the culture supernatant of RAW 264.7 cells. The IL-1 $\beta$ concentration was maximal at the $10 \%$ dilution after 24 hours of stimulation with CSE and DEP (Fig. 1). RAW cells and elastase-treated lung explants were stimulated with $10 \%$ CSE, DEPs, and $1 \mathrm{mg} / \mathrm{mL}$ LPS with or without $10 \mu \mathrm{M}$ $\mathrm{N}$-acetylcysteine (NAC) or $100 \mu \mathrm{M}$ of the caspase-1 inhibitor, Z-YVAD-FMK (Calbiochem, Darmstadt, Germany).

\section{Bronchoalveolar lavage}

BAL was performed as described previously [19]. Briefly, BAL fluid was obtained by instilling a total volume of 1.5-mL saline into the lungs three times through a tracheal tube. The BAL fluid was centrifuged $(150 \times \mathrm{g}, 10$ minutes, $4^{\circ} \mathrm{C}$ ), and the cell pellet was resuspended in 1 $\mathrm{mL}$ of PBS. A $50-\mu \mathrm{L}$ volume of the suspension was mixed with the same volume of $4 \%$ trypan blue to determine the cell numbers and viability. To perform differential cell counts in BAL fluid, $5 \times 10^{3}$ cells were mounted on a slide by cytocentrifugation and stained with Diff-Quik (Baxter Healthcare, Miami, FL, USA).

\section{Tissue preparation and fixation}

Following BAL, the chest wall was opened. The lungs were inflated with $10 \%$ phosphate-buffered formalin at a transpulmonary pressure of $25 \mathrm{cmH}_{2} \mathrm{O}$ for 1 hour. The tissues were embedded in paraffin wax and were cut for
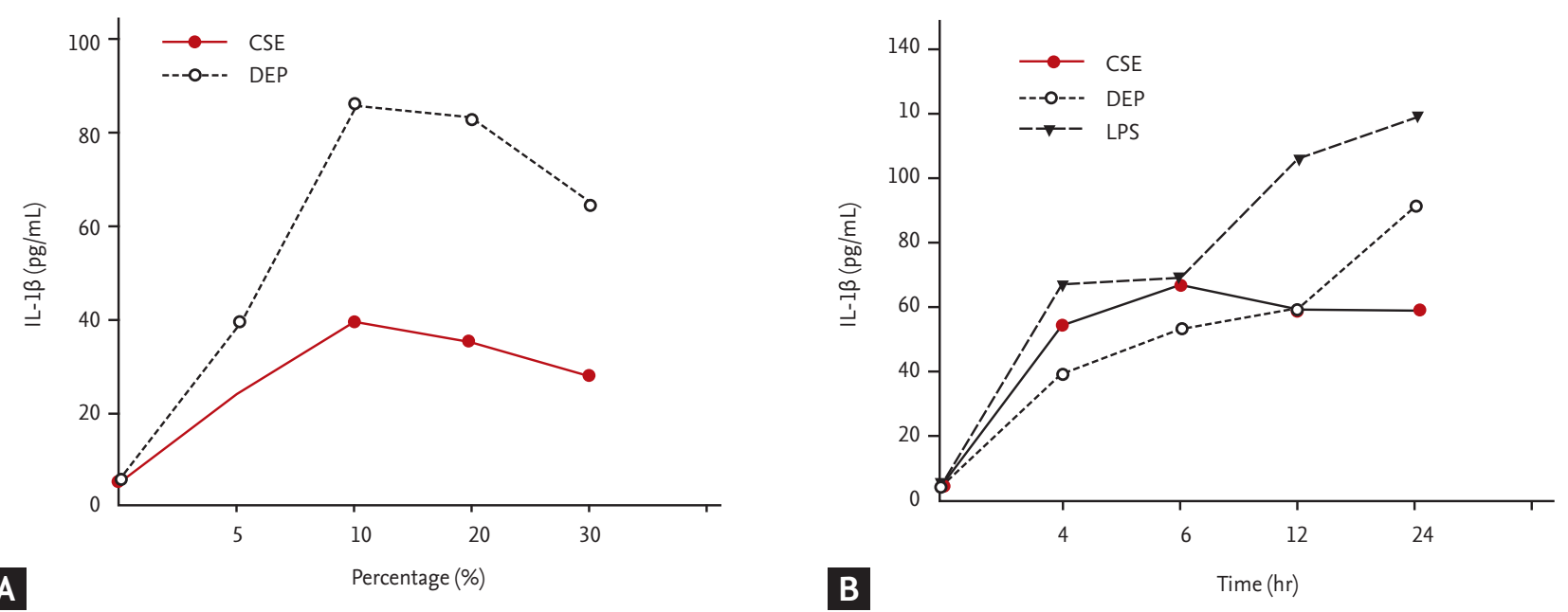

Figure 1. (A) Interleukin-1 $\beta$ (IL-1 $\beta$ ) secretion by RAW 264.7 cells after 24 -hour incubation with various concentrations of cigarette smoking extract (CSE) and diesel exhaust particles (DEPs). IL-1 $\beta$ secretion peaked at a 1:10 dilution of both CSE and DEPs. (B) IL-1 $\beta$ secretion by RAW 264.7 cells at 4 to 24 hours in the presence of a 1:10 dilution of CSE, DEPs, or $1 \mathrm{mg} / \mathrm{mL}$ lipopolysaccharide (LPS). IL-1 $\beta$ secretion peaked at 24 hours for LPS and DEPs; however, CSE resulted in a plateau after 6 hours. The data shown are representative of three independent experiments. 
H\&E staining. Cultured lung tissue explants were embedded in paraffin wax blocks and were cut for immunohistochemical staining for $\mathrm{NLRP}_{3}$ and caspase-1.

\section{IL-1 $\beta$ assay}

Cell and tissue culture supernatants were collected by centrifugation to remove cellular debris. Supernatants were stored as aliquots at $-70^{\circ} \mathrm{C}$ until use. IL-1 $\beta$ was assayed using a Quantikine ELISA kit (R\&D Systems, Minneapolis, MN, USA), as described by the manufacturer.

\section{Mean linear intercept}

To calculate the change in alveolar destruction, we measured the air space size using the mean linear intercept (MLI) according to a modified method described previously [20]. Briefly, after paraffin embedding, $5-\mu \mathrm{m}$ sections were cut and stained with H\&E. Ten randomly selected fields under the magnification of 10ox were assessed from each lung. Fifteen lines were randomly placed on the lung sections, and the number of intercepts crossing the alveolar wall was counted. The MLI was calculated from the length of the lines multiplied by the number of the lines divided by the sum of all counted intercepts.

\section{Immunohistochemistry}

A VectaStatin rabbit ABC Elite kit (Vector Laboratories, Burlingame, CA, USA) was used for immunostaining. Tissue sections ( $5 \mu \mathrm{m}$ ) were deparaffinized, endogenous peroxidase was blocked with $1.4 \% \mathrm{H}_{2} \mathrm{O}_{2}$ in methyl alcohol for 30 minutes, and nonspecific binding was blocked with $1.5 \%$ normal rabbit serum for 30 minutes. The sections were incubated with rabbit polyclonal anti-mouse NLRP3-inflammasome antibody (1:500; Abnova, Taipei, Taiwan) at $4^{\circ} \mathrm{C}$ for 16 hours. After washing with Tris-buffered saline (TBS), the sections were sequentially incubated with biotinylated rabbit anti-rabbit immunoglobulin G (H+L) (1:200; Vector Laboratories) and avidin-biotin peroxidase complex (1:50; ABC kit, Vector Laboratories) for 30 minutes. The color reaction was developed with 3,3'-diamino-benzidine tetrachloride (Zymed Laboratories, South San Francisco, CA, USA), and Harris hematoxylin was applied as a counter stain.

\section{Western blotting}

A $10 \mu \mathrm{g}$ of protein from lung tissue sample was electro- phoresed on $15 \%$ polyacrylamide gels using a discontinuous system. The proteins were transferred to nitrocellulose membranes at $120 \mathrm{~V}$ for 40 minutes. After blocking in 5\% skim milk and $0.1 \% \mathrm{NP}_{4} \mathrm{O}$ in TBS for 2 hours at room temperature, the membranes were incubated with a rabbit polyclonal anti-mouse NLRP3-inflammasome (Abnova) or rabbit monoclonal anti-mouse caspase-1 (Abcam, Cambridge, MA, USA) primary antibody. The membrane was incubated with horseradish peroxidase (HRP)-conjugated anti-rabbit immunoglobulin $\mathrm{G}$ (1:2,00o dilution) for 1 hour at room temperature. The target protein was detected using an enhanced chemiluminescence reagent (Amersham Pharmacia Biotech, Little Chalfont, UK).

\section{RESULTS}

\section{IL-1 $\beta$ secretion by RAW 264.7 cells after stimulation with CSE and DEPs}

IL-1 $\beta$ concentrations in the supernatants of RAW 264.7 cells were measured after stimulation with 10\% CSE and DEPs (Fig. 1). CSE and DEP exposure led to marked IL-1 $\beta$ secretion. To evaluate the effects of oxidants and caspase-1 on IL-1 $\beta$ secretion, cells were incubated

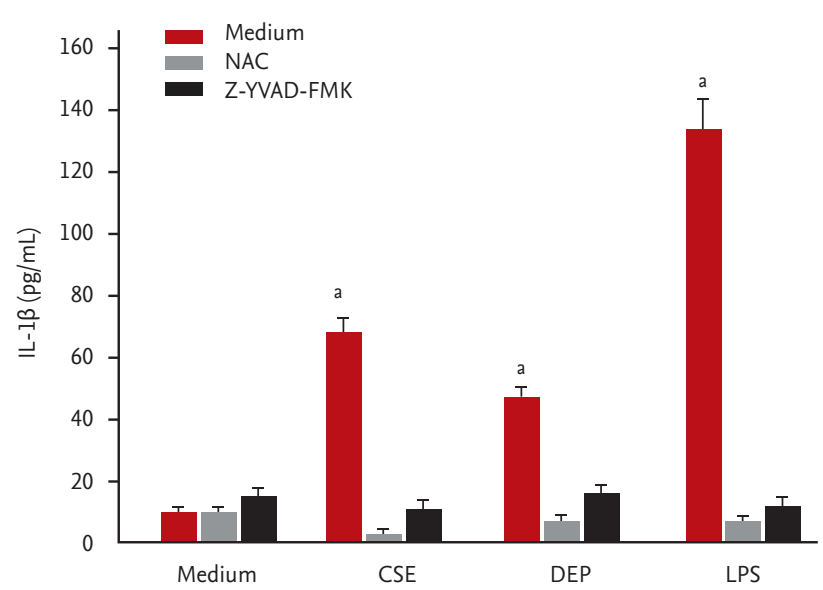

Figure 2. Interleukin-1 $\beta$ (IL-1 $\beta$ ) secretion by RAW 264.7 cells after 24-hour stimulation with cigarette smoking extract (CSE) and diesel exhaust particles (DEPs) in the presence or absence of $\mathrm{N}$-acetylcysteine (NAC) or a caspase-1 inhibitor. CSE-, DEP-, and lipopolysaccharide (LPS)-induced increases in IL-1 $\beta$ levels in the supernatants of RAW 264.7 cells were significantly decreased by NAC and Z-YVAD-FMK. ${ }^{a} p<0.01$ vs. NAC and Z-YVAD-FMK. 

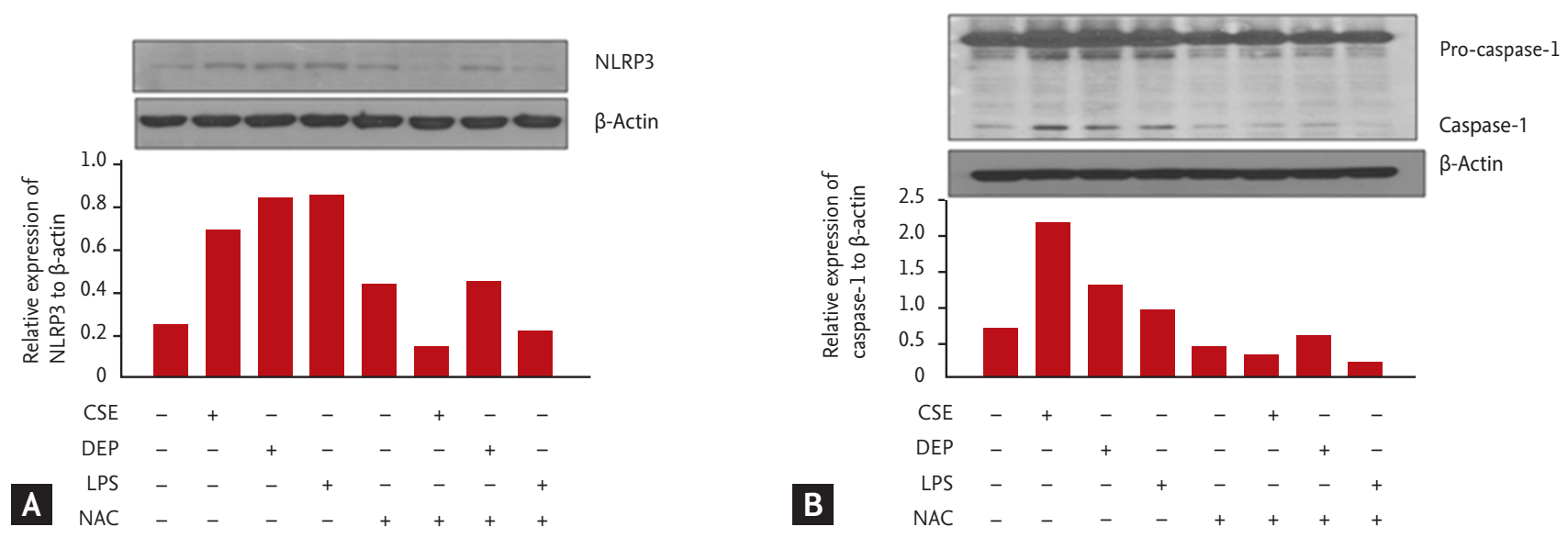

Figure 3. Western blot analysis of (A) nucleotide-binding oligomerization domain-like receptor (NLR) family members containing the pyrin domain (NLRP3)-inflammasome and (B) caspase-1 levels after stimulation with cigarette smoking extract (CSE) and diesel exhaust particles (DEPs). (A) NLRP3-inflammasome levels in RAW 264.7 cells were increased following stimulation with CSE and DEP for 24 hours, but were decreased by N-acetylcysteine (NAC) application. (B) Caspase-1 levels in RAW 264.7 cells were increased following stimulation with CSE and DEPs for 24 hours. This expression was decreased by NAC. Lipopolysaccharide (LPS) was used as positive control.

with the antioxidant NAC and the caspase-1 inhibitor Z-YVAD-FMK for 24 hours. The IL-1 $\beta$ concentrations were decreased significantly in the supernatants of RAW 264.7 cells by the antioxidant and the caspase-1 inhibitor $(p<0.05)$ (Fig. 2).

\section{NLRP3-inflammasome and caspase-1 protein levels in RAW $\mathbf{2 6 4 . 7}$ cells after stimulation with CSE and DEPs}

We evaluated whether NLRP3-inflammasome and caspase-1 levels in RAW 264.7 cells were upregulated by stimulation with CSE and DEPs by Western blotting. NLRP3-inflammasome expression was increased by stimulation with DEPs and CSE and inhibited by the antioxidant NAC (Fig. 3A). Caspase-1 expression was upregulated by CSE and DEPs and decreased in the presence NAC (Fig. 3B).

\section{Cellular profiles, histology, and morphometric anal- ysis of an elastase-induced emphysema model}

The total cell count in BAL fluid was not different between the control group and elastase-induced emphysema group. The lymphocyte numbers significantly increased in the emphysema group compared with the control group, but the numbers of other cell types were not different between the two groups (Fig. 4). The architecture of

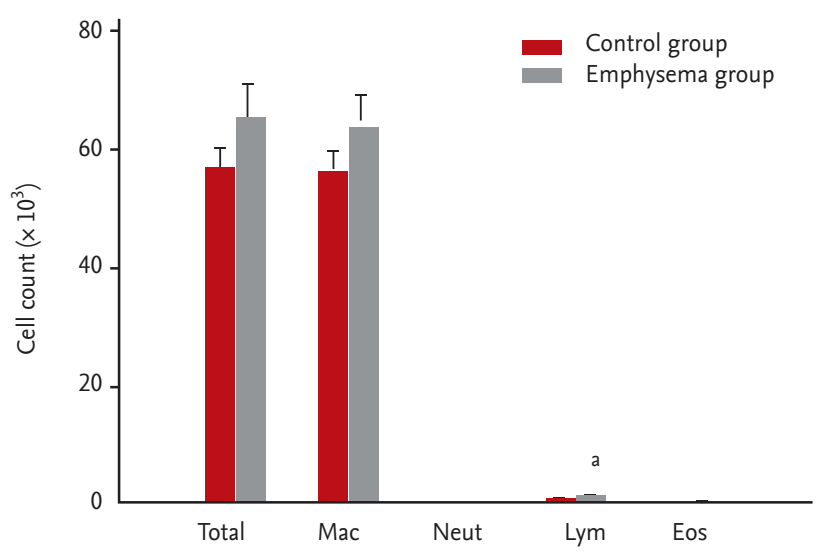

Figure 4. Total cell and inflammatory cell counts in bronchoalveolar lavage fluid from the control and emphysema groups. Lymphocyte numbers were significantly increased in the emphysema group compared with the control group. The numbers of other cell types were not different between the two groups. Total, total cell count; Mac, macrophages; Neut, neutrophils; Lym, lymphocytes; Eos, eosinophils. ${ }^{\mathrm{a}} \mathrm{p}<$ 0.05 vs. the control group.

alveolar septa and the airspace was well preserved in the control group (Fig. 5A). However, in the elastin-induced emphysema group, alveoli were enlarged (Fig. ${ }_{5} \mathrm{~B}$ ). The MLI was significantly higher in the elastin-induced emphysema group than in the control group $(90.4 \pm 6.7 \mu \mathrm{m}$ vs. $23.6 \pm 2.2 \mu \mathrm{m}, p<0.01$ ) (Fig. $5 \mathrm{C}$ ). 

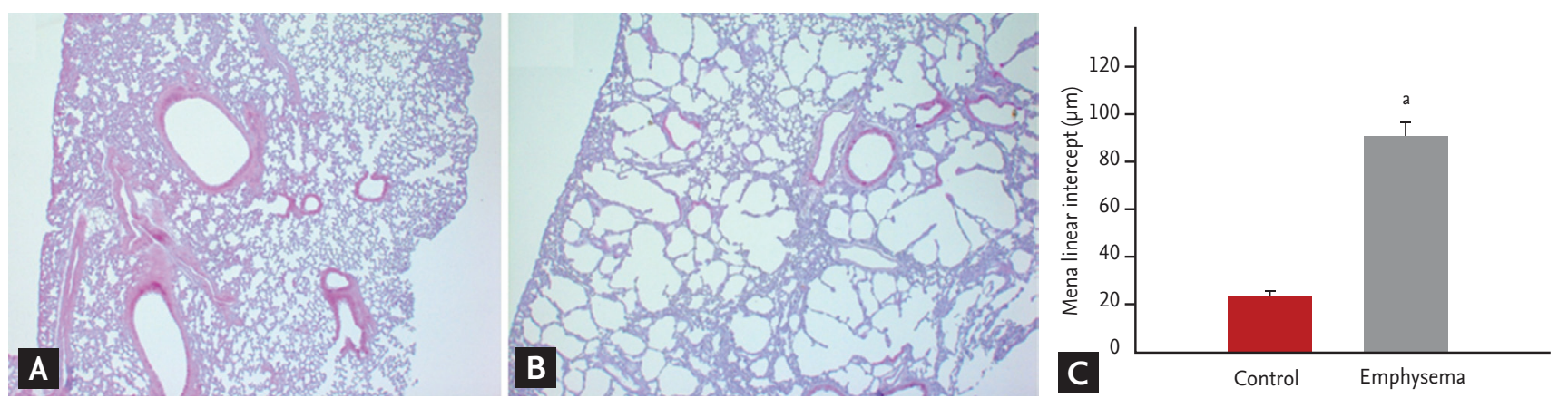

Figure 5. (A, B) Hematoxylin-eosin staining of the lung $(\times 40)$ and $(\mathrm{C})$ the mean linear intercepts of both groups. (A) The architecture of alveolar septa and the airspace was well preserved in the control group, and (B) the alveoli were enlarged in the elastin-induced emphysema group. (C) The mean linear intercept was significantly higher in the elastin-induced emphysema group than that in the control group. ${ }^{a} p<0.01$ vs. the control group.

Normal mice

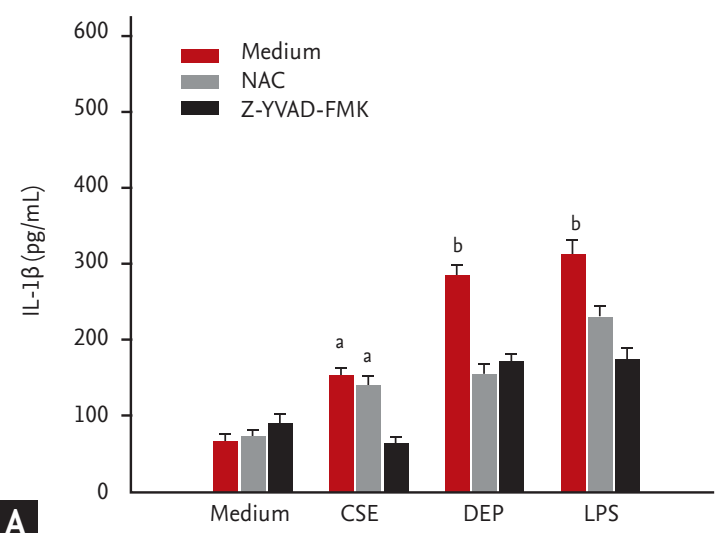

Emphysema mice

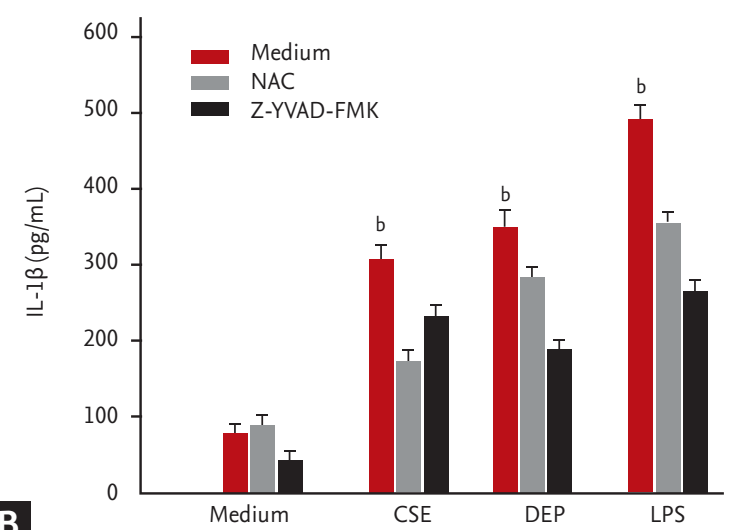

Figure 6. Interleukin-1 $\beta$ (IL-1 $\beta$ ) secretion from lung tissues after 24 hours stimulation with cigarette smoking extract (CSE) and diesel exhaust particles (DEPs). (A) CSE and DEP exposure increased IL-1 $\beta$ secretion in both the normal and (B) elastin-induced emphysema groups. N-acetylcysteine (NAC) and Z-YVAD-FMK inhibited the NAC- and DEP-induced IL-1 $\beta$ secretion in both the normal and elastin-induced emphysema groups. LPS, lipopolysaccharide. ${ }^{\mathrm{a}} \mathrm{p}<0.05$ vs. Z-YVAD-FMK, ${ }^{\mathrm{b}} \mathrm{p}<0.05$ vs. NAC and Z-YVAD-FMK.

\section{IL-1 $\beta$ secretion from lung tissue explants after stim- ulation with CSE and DEPs}

Murine lung tissue explants from the normal and elastase-induced emphysema groups were incubated with CSE and DEPs for 24 hours; the IL-1 $\beta$ levels in supernatants were then measured. Similar to RAW 264.7 cells, CSE and DEPs increased the secretion of IL-1 $\beta$ by the cultured lung tissue explants obtained from the normal (Fig. 6A) and elastase-induced emphysema groups (Fig. 6B). IL-1 $\beta$ secretion by CSE and DEPs increased more in the elastase-induced emphysema group than in the normal group (CSE: $309 \pm 19 \mathrm{pg} / \mathrm{mL}$ vs. $151 \pm 13 \mathrm{pg} / \mathrm{mL}$, respectively, $p<0.05$; DEP: $350 \pm 24 \mathrm{pg} / \mathrm{mL}$ vs. $281 \pm 15$ $\mathrm{pg} / \mathrm{mL}$, respectively, $p<0.05)$. NAC and Z-YVAD-FMK significantly inhibited the NAC- and DEP-induced IL$1 \beta$ secretion in both the normal and elastase-induced emphysema groups (Fig. 6).

\section{Immunohistochemical staining of the NLRP3-in- flammasome in lung tissues after stimulation with CSE and DEPs}

$\mathrm{NLRP}_{3}$-inflammasome expression was detected in lung tissue explants after 24 hours of stimulation with CSE and DEP. The NLRP3 expression was increased by CSE and DEP in both the normal (Fig. 7A) and elastase-induced emphysema group (Fig. 7B). This expression was suppressed by NAC in both the normal and emphysema groups. 


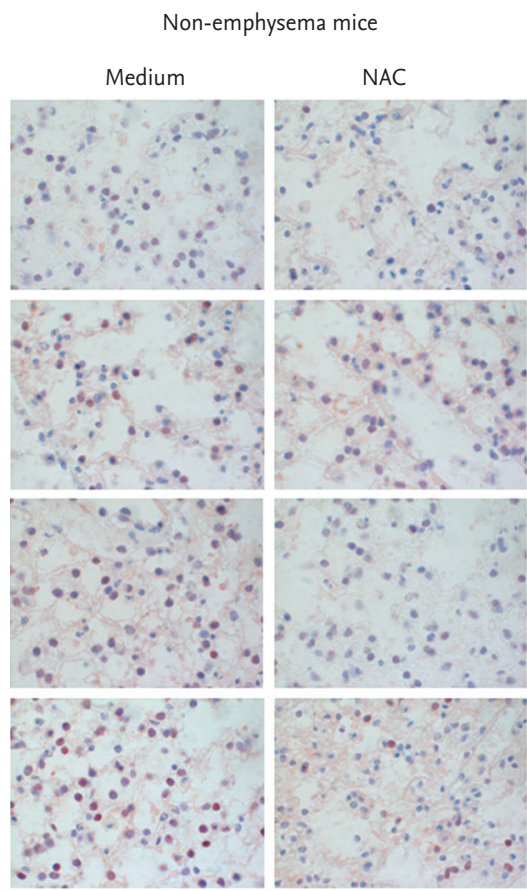

A

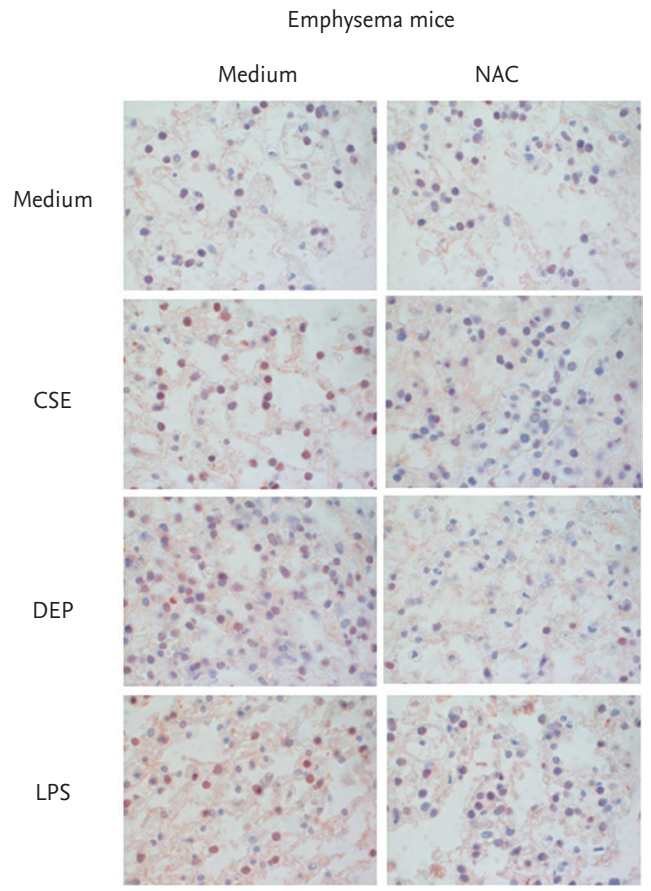

B
Figure 7. Immunohistochemical staining of the nucleotide-binding oligomerization domain-like receptor (NLR) family members containing the pyrin domain 3 (NLRP3)-inflammasome in lung tissues after 24-hour stimulation with cigarette smoking extract (CSE) and diesel exhaust particles (DEPs) (×100). (A) NLRP3-inflammasome expression was increased by CSE and DEPs in both the normal and (B) elastin-induced emphysema groups. NLRP3-inflammasome expression was suppressed by N-acetylcysteine (NAC) in both the normal and emphysema groups. LPS, lipopolysaccharide.

\section{DISCUSSION}

The present study showed that the NLRP3-inflammasome was upregulated by DEPs and/or CSE, and this upregulation was inhibited by the antioxidant: NAC. The exact role of NLRP3-inflammasome is unclear in the pathogenesis of AECOPD, but oxidative stress may be involved because the antioxidant NAC inhibited the DEP-induced increase in IL-1 $\beta$ levels in a macrophage cell line, and because the $\mathrm{NLRP}_{3}$-inflammasome overexpressed in the elastase-induced emphysema model. Other animal studies have suggested a relationship between DEPs and oxidative stress. Intratracheal instillation of DEPs increased the levels of a superoxide producer (nicotinamide adenine dinucleotide phosphate cytochrome P-450 reductase) and decreased those of a superoxide scavenger (superoxide dismutase) in mice [21]. Although few reports have been published regarding the direct demonstration of inflammasome activation in the lung tissues from patients with COPD at acute exacerbation, activation of NLRP3-inflammasome is likely a key player in the pathogenesis of acute exacerbations. The NLRP3-inflammasome was upregulated during nontypeable $\mathrm{H}$. influenzae-induced inflammation in respiratory cells and human lung tissues $[11]$. In the present study, we found that the NL-
$\mathrm{RP}$ 3-inflammasome was upregulated by treatment with DEPs in the lung tissue explants of murine elastase-induced emphysema, which mimics human emphysema. These findings suggest the NLRP3-inflammasome play an important role in DEP-induced inflammation in elastase-induced emphysema animal model.

It is suggested that a two-step reaction is required for the full activation of $\mathrm{NLRP}_{3}$-inflammasome [22,23]. First step is 'priming' which upregulate pro-IL-1 $\beta$, proIL-18, and the components of inflammasome. Second step is 'activation' which is the assembly of the components into inflammasome structure and production of proinflammatory interleukins. The exact mechanism of activation of inflammasome is unknown, but, a lot of stimuli like microbes and microbial substances, LPS, are found to activate $\mathrm{NLRP}_{3}$ in the presence of adenosine triphosphate [24]. By these reasons, we used LPS as positive control for activation of NLRP3 in the present study.

Air pollution is a known precipitating factor of AECOPD [25,26]. Epidemiologic studies have supported the role of air pollutants, such as nitrogen dioxide $\left(\mathrm{NO}_{2}\right)$, sulfur dioxide $\left(\mathrm{SO}_{2}\right)$, particulate matter smaller than $10 \mu \mathrm{g}\left(\mathrm{PM}_{10}\right)$, and black smoke particulate matter, in the increase in respiratory symptoms and mortality rate in COPD patients [27]. Exposure of healthy persons 
to diesel exhaust results in an increased number of neutrophils in sputum [28], and an in vitro study showed an increase in the levels of IL-1 and neutrophil-related cytokines, such as IL-8 and granulocyte-macrophage colony-stimulating factor, in human airway epithelial cells [29,30]. Urban particulate matter including dust and emission particles has been shown to activate the NLRP3-inflammasome in airway epithelium [31]. In the present study, the IL-1 $\beta$ level was increased by treatment with DEPs in both cell lines and an elastase-induced emphysema model. These findings are compatible with alterations in IL-1 $\beta$ levels in $\mathrm{H}_{1} \mathrm{~N}_{1}$ virus-associated AECOPD in animal models [32] and in a cohort of patients with COPD [33].

Intratracheal administration of PPE can induce acute lung inflammation due to increased secretion of inflammatory cytokines, such as IL-1 $\beta$ and IL- 6 , during the acute stage [34]. However, in the present study, we euthanized the mice at 3 weeks after intratracheal instillation of elastase, and the neutrophil count in BAL was similar in the emphysema and saline-treated groups. Therefore, elastase had no marked effect on the expression of the $\mathrm{NLRP}_{3}$-inflammasome and lung inflammation.

Our data demonstrated that CSE increased IL-1 $\beta$ secretion in the emphysema model; however, in the control group, IL-1 $\beta$ secretion did not attain the level reached in the emphysema mode (Fig. 6). This finding may be due to secretion of various cytokines by activated alveolar macrophages following cigarette smoke exposure [35]. We expected DEPs to show a pattern of IL-1 $\beta$ secretion similar to CSE; however, DEPs increased IL-1 $\beta$ levels to a degree similar to that in both the emphysema and non-emphysema models (Fig. 6). A study involving intratracheal instillation of DEPs in an elastase-induced emphysema model showed no difference in the IL-1 $\beta$ level between the emphysema and control groups [34], which is in agreement with our findings.

Caspase-1 levels are increased in the lung tissues of patients with COPD compared with those from nonsmokers [36], serving as indirect evidence of the role of the inflammasome in the pathogenesis of COPD. However, no reports involving direct measurement of inflammasome expression in COPD lung tissues are available. Thus, in the present study, the elevated inflammasome levels induced by DEPs in both epithelial cell lines and an elastase-induced emphysema model may be related more closely to AECOPD than its pathogenesis.

The limitations of this study were as follows. First, experiments using NAC should be interpreted with caution. NAC may detoxify other reactive DEP constituents that could trigger inflammatory reactions and suppress reactive oxygen species, which are important mediators in most signal transduction pathways $[37,38]$. Thus DEP-induced overexpression of the NLRP3-inflammasome may be related to factors other than oxidative stress. Second, the normal ambient DEP concentrations are typically lower than those used in this study. We attempted to generate model of DEP-induced AECOPD, but inducing lung inflammation using a low concentration of DEPs is problematic. Other studies with human volunteers have also used a DEP concentration higher that the ambient $[39,40]$. Third, we did not measure lung mechanical parameters such as enhanced pause (Penh) and total respiratory systemic resistance. Although we did not measure lung mechanics, the increased MLI could be a good indicator of emphysema. Fourth, the concentration of DEP used in the present study is higher than those in ambient air. We tried to reduce the dose of DEP in the present study, but we should choose higher concentration of DEP by the finding of the dose-response curve shown in Fig. 1.

In conclusion, these data suggest that the NLRP3-inflammasome was activated by challenge with DEPs in an elastase-induced emphysema model. Furthermore, an antioxidant inhibited the DEP-induced activation of the NLRP3-inflammasome.

\section{KEY MESSAGE}

1. The nucleotide-binding oligomerization domain-like receptor (NLR) family members containing the pyrin domain 3 (NLRP3)-inflammasome is activated by diesel exhaust particles in ex vivo tissue explants from elastase-induced emphysema animal model, and this activation is inhibited by $\mathrm{N}$-acetylcysteine.

2. Diesel exhaust particles could be an important cause of acute exacerbation of chronic obstructive pulmonary disease through activation of NLRP3-inflammasome. 


\section{Conflict of interest}

No potential conflict of interest relevant to this article was reported.

\section{Acknowledgments}

This work was supported by grants from the National Research Foundation of Korea (2017R1A2B4012693) and Soon Chun Hyang University Research Fund. All of the bio-specimens and clinical data were obtained from the National Biobank of Korea and the regional biobank at Soon Chun Hyang University Bucheon Hospital.

\section{REFERENCES}

1. Global Initiative for Chronic Obstructive Lung Disease (GOLD). Global strategy for the diagnosis, management and prevention of COPD, 2011 [Internet]. GOLD, c2016 [cited $2017 \mathrm{Jul}$ 7]. Available from: http://www.goldcopd.org.

2. Chapman KR, Mannino DM, Soriano JB, et al. Epidemiology and costs of chronic obstructive pulmonary disease. Eur Respir J 2006;27:188-207.

3. Patil SP, Krishnan JA, Lechtzin N, Diette GB. In-hospital mortality following acute exacerbations of chronic obstructive pulmonary disease. Arch Intern Med 2003;163:1180-1186.

4. Berkius J, Nolin T, Mardh C, Karlstrom G, Walther SM; Swedish Intensive Care Registry. Characteristics and long-term outcome of acute exacerbations in chronic obstructive pulmonary disease: an analysis of cases in the Swedish Intensive Care Registry during 2002-2006. Acta Anaesthesiol Scand 2008;52:759-765.

5. De Nardo D, De Nardo CM, Latz E. New insights into mechanisms controlling the $\mathrm{NLRP}_{3}$ inflammasome and its role in lung disease. Am J Pathol 2014;184:42-54.

6. Dinarello CA. Immunological and inflammatory functions of the interleukin-1 family. Annu Rev Immunol 2009;27:519-550.

7. Kuschner WG, D'Alessandro A, Wong H, Blanc PD. Dosedependent cigarette smoking-related inflammatory responses in healthy adults. Eur Respir J 1996;9:1989-1994.

8. Rovina N, Dima E, Gerassimou C, Kollintza A, Gratziou C, Roussos C. Interleukin-18 in induced sputum: association with lung function in chronic obstructive pulmonary disease. Respir Med 2009;103:1056-1062.

9. Imaoka H, Hoshino T, Takei S, et al. Interleukin-18 pro- duction and pulmonary function in COPD. Eur Respir J 2008;31:287-297.

10. Decramer M, Janssens W, Miravitlles M. Chronic obstructive pulmonary disease. Lancet 2012;379:1341-1351.

11. Rotta Detto Loria J, Rohmann K, Droemann D, et al. Nontypeable Haemophilus influenzae infection upregulates the NLRP 3 inflammasome and leads to caspase-1-dependent secretion of interleukin-1 $\beta$ : a possible pathway of exacerbations in COPD. PLoS One 2013;8:e66818.

12. Torres-Duque C, Maldonado D, Perez-Padilla R, Ezzati M, Viegi G; Forum of International Respiratory Studies (FIRS) Task Force on Health Effects of Biomass Exposure. Biomass fuels and respiratory diseases: a review of the evidence. Proc Am Thorac Soc 2008;5:577-590.

13. Sydbom A, Blomberg A, Parnia S, Stenfors N, Sandstrom T, Dahlen SE. Health effects of diesel exhaust emissions. Eur Respir J 2001;17:733-746.

14. Bayram H, Devalia JL, Sapsford RJ, et al. The effect of diesel exhaust particles on cell function and release of inflammatory mediators from human bronchial epithelial cells in vitro. Am J Respir Cell Mol Biol 1998;18:441-448.

15. Ghio AJ, Richards JH, Carter JD, Madden MC. Accumulation of iron in the rat lung after tracheal instillation of diesel particles. Toxicol Pathol 2000;28:619-627.

16. Zhou R, Yazdi AS, Menu P, Tschopp J. A role for mitochondria in $\mathrm{NLRP}_{3}$ inflammasome activation. Nature 2011;469:221-225.

17. Khedoe PP, Wong MC, Wagenaar GT, et al. The effect of PPE-induced emphysema and chronic LPS-induced pulmonary inflammation on atherosclerosis development in

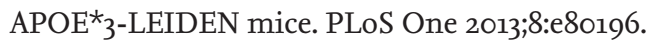

18. Smelter DF, Sathish V, Thompson MA, Pabelick CM, Vassallo R, Prakash YS. Thymic stromal lymphopoietin in cigarette smoke-exposed human airway smooth muscle. J Immunol 2010;185:3035-3040.

19. Haque R, Umstead TM, Freeman WM, Floros J, Phelps DS. The impact of surfactant protein-A on ozone-induced changes in the mouse bronchoalveolar lavage proteome. Proteome Sci 2009;7:12.

20. Luthje L, Raupach T, Michels H, et al. Exercise intolerance and systemic manifestations of pulmonary emphysema in a mouse model. Respir Res 2009;10:7.

21. Lim HB, Ichinose T, Miyabara Y, et al. Involvement of superoxide and nitric oxide on airway inflammation and hyperresponsiveness induced by diesel exhaust particles in mice. Free Radic Biol Med 1998;25:635-644. 
22. Gross O, Thomas CJ, Guarda G, Tschopp J. The inflammasome: an integrated view. Immunol Rev 2011;243:136-151.

23. Bauernfeind F, Ablasser A, Bartok E, et al. Inflammasomes: current understanding and open questions. Cell Mol Life Sci 2011;68:765-783.

24. Kanneganti TD, Ozoren N, Body-Malapel M, et al. Bacterial RNA and small antiviral compounds activate caspase-1 through cryopyrin/Nalp3. Nature 2006;440:233236.

25. Peacock JL, Anderson HR, Bremner SA, et al. Outdoor air pollution and respiratory health in patients with COPD. Thorax 2011;66:591-596.

26. Ling SH, van Eeden SF. Particulate matter air pollution exposure: role in the development and exacerbation of chronic obstructive pulmonary disease. Int J Chron Obstruct Pulmon Dis 2009;4:233-243.

27. Papi A, Luppi F, Franco F, Fabbri LM. Pathophysiology of exacerbations of chronic obstructive pulmonary disease. Proc Am Thorac Soc 2006;3:245-251.

28. Nordenhall C, Pourazar J, Blomberg A, Levin JO, Sandstrom T, Adelroth E. Airway inflammation following exposure to diesel exhaust: a study of time kinetics using induced sputum. Eur Respir J 2000;15:1046-1051.

29. Ohtoshi T, Takizawa H, Okazaki H, et al. Diesel exhaust particles stimulate human airway epithelial cells to produce cytokines relevant to airway inflammation in vitro. J Allergy Clin Immunol 1998;101(6 Pt 1):778-785.

30. Ritz SA, Wan J, Diaz-Sanchez D. Sulforaphane-stimulated phase II enzyme induction inhibits cytokine production by airway epithelial cells stimulated with diesel extract. Am J Physiol Lung Cell Mol Physiol 2007;292:L33-L39.

31. Hirota JA, Hirota SA, Warner SM, et al. The airway epithelium nucleotide-binding domain and leucine-rich repeat protein 3 inflammasome is activated by urban particulate matter. J Allergy Clin Immunol 2012;129:1116-1125.
32. Bauer CM, Zavitz CC, Botelho FM, et al. Treating viral exacerbations of chronic obstructive pulmonary disease: insights from a mouse model of cigarette smoke and $\mathrm{H}_{1} \mathrm{~N}_{1}$ influenza infection. PLoS One 2010;5:e13251.

33. Bauer CM, Morissette MC, Stampfli MR. The influence of cigarette smoking on viral infections: translating bench science to impact COPD pathogenesis and acute exacerbations of COPD clinically. Chest 2013;143:196-206.

34. Inoue K, Koike E, Takano H. Comprehensive analysis of elastase-induced pulmonary emphysema in mice: effects of ambient existing particulate matters. Int Immunopharmacol 2010;10:1380-1389.

35. Castro P, Legora-Machado A, Cardilo-Reis L, et al. Inhibition of interleukin-ıbeta reduces mouse lung inflammation induced by exposure to cigarette smoke. Eur J Pharmacol 2004;498:279-286.

36. Eltom S, Stevenson CS, Rastrick J, et al. $\mathrm{P}_{2} \mathrm{X}_{7}$ receptor and caspase 1 activation are central to airway inflammation observed after exposure to tobacco smoke. PLoS One 2011;6:e24097.

37. Sauer H, Wartenberg M, Hescheler J. Reactive oxygen species as intracellular messengers during cell growth and differentiation. Cell Physiol Biochem 2001;11:173-186.

38. Schwarze PE, Totlandsdal AI, Lag M, Refsnes M, Holme JA, Ovrevik J. Inflammation-related effects of diesel engine exhaust particles: studies on lung cells in vitro. Biomed Res Int 2013;2013:685142.

39. Rudell B, Blomberg A, Helleday R, et al. Bronchoalveolar inflammation after exposure to diesel exhaust: comparison between unfiltered and particle trap filtered exhaust. Occup Environ Med 1999;56:527-534.

40. Rudell B, Ledin MC, Hammarstrom U, Stjernberg N, Lundback B, Sandstrom T. Effects on symptoms and lung function in humans experimentally exposed to diesel exhaust. Occup Environ Med 1996;53:658-662. 